Results Among 6318 females recorded as testing negative for CT/ NG, 24\% had an annual test (highest in 16-19 year olds at 26\%), compared with $15 \%$ of 4241 males (highest in 20-24 year olds at $19 \%)$. Factors independently and significantly $(p<0.05)$ associated with annual testing were female gender (adjusted odds ratio (AOR): 1.7, 95\% CI: $1.5-1.9$ ), age $20-24$ years (AOR:1.5, 95\% CI: $1.2-1.9$ ), services with $>90 \%$ of clients

Aboriginal (AOR:1.4.95\% CI: 1.2-1.6), services having an electronic medical record system (AOR:1.7.95\% CI: 1.4-2.1), services using a centralised recall system (AOR:1.3.95\% CI: 1.1-1.6), services being community controlled (health centre governance controlled by a local Aboriginal board) (AOR:1.4, 95\% CI: 1.2-1.6) and Aboriginal health worker/s employed (AOR1.4.95\% CI: 1.0 -1.9).

Conclusions Our analysis identified both client and service related factors associated with higher levels of annual testing. Having Aboriginal staff members and systems which support patient recall were key factors identified for services that are amenable to change. While some factors may be indirect markers of other characteristics of the health centres or clients, these findings will help guide support to services in remote areas.

\section{P5.008 PERFORMANCE OF ANTENATAL SCREENING FOR HIV AND SYPHILIS IN EU/EEA, DURING 2006-2011: MAKING USE OF SURVEILLANCE DATA}

doi:10.1136/sextrans-2013-051184.1055

O Sfetcu, A Cleeve, G Likatavicius, G Spiteri, M van de Laar. ECDC, European Centre for Disease Prevention and Control, Stockholm, Sweden

Introduction Although majority of countries in the European Union (EU/EEA) offer antenatal screening for HIV and syphilis, mother-to-child transmission (MTCT) is still occurring. We aim to analyse the performance and effectiveness of antenatal screening programmes to strengthen these programmes across the EU/EEA. Methods Surveillance for HIV and syphilis, including congenital syphilis (CS), in EU/EEA is coordinated by the European Centre for Disease Prevention and Control. Data reported by Member States covering the period 2006-2011 were analysed. Information on country of birth and probable country of infection were used to identify where HIV transmission might have occurred. Rates of HIV and CS per 100,000 live births as well as rates of HIV and syphilis among women of reproductive age (15-49 years) were used to compare mother-to-child transmission across the EU/EEA.

Results In 2006-2011, 592 cases of HIV-MTCT and 566 CS were reported (rate: $1.8 / 100000$ population and 2.0/100000 respectively). 41393 cases of HIV infection and 18750 cases of syphilis were reported in women of reproductive age (rates: 5.7/100000 and $3.1 / 100000$, respectively). Cases of HIV-MTCT and CS were reported by 20 and 16 countries respectively. Rates ranged between 0.2 and 21.8 for HIV and 0.1 and 39.8 for CS. Rates of HIV-MTCT and HIV in women of reproductive age were higher than the EU/ EEA average in France, Latvia, Portugal and the UK. Similarly, rates of CS and syphilis were higher than the EU/EEA average in Bulgaria, Latvia, Romania, Lithuania and Slovakia.

Conclusions Surveillance data suggest an unequal performance across EU/EEA in preventing mother-to-child transmission of HIV and syphilis. Understanding of the epidemiological determinants at national level, identification of pregnant women with high HIV and syphilis burden and barriers for access to antenatal care, will inform revision of antenatal screening practices and will allow strengthening of prevention interventions towards key populations.

\section{P5.009 PERFORMANCE OF CERVICAL CANCER SCREENING TESTS IN HIV POSITIVE WOMEN IN AFRICA: INFLUENCE OF CD4 COUNTS}

doi:10.1136/sextrans-2013-051184.1056

'S Delany, ${ }^{2 \mathrm{H}} \mathrm{A}$ Weiss, ${ }^{3} \mathrm{O}$ Lompo, ${ }^{4} \mathrm{~S}$ Doutre, ${ }^{1} \mathrm{~T}$ Omar, ${ }^{2 \mathrm{H}}$ Kelly, ${ }^{3} \mathrm{~S}$ Zan, ${ }^{1} \mathrm{P}$ Michelow, ${ }^{4} \mathrm{~V}$ Costes, ${ }^{2 P}$ Mayaud. 'Wits Reproductive Health and HIV Institute, Johannesburg, South Africa; 'London School of Hygiene \& Tropical Medicine, London, UK; ${ }^{3}$ Centre de Recherche Internationale sur la Sante, Ouagadougou, Burkina Faso; ${ }^{4}$ University of Montpellier 1 \& INSERM U1058, Montpellier, France

Background To evaluate strategies for cervical cancer screening among HIV-positive African women, against histological CIN endpoints.

Abstract P5.009 Table 1 Prevalence of CIN2+, and performance of screening tests singly or in combination by CD4 + count among HIV-positive women in Burkina Faso and South Africa

\begin{tabular}{|c|c|c|c|c|}
\hline & CD4 $<200$ cells $/ \mu \mathrm{L}$ & CD4 200-349 cells $/ \mu \mathrm{L}$ & CD4 $\geq 350$ cells $/ \mu \mathrm{L}$ & P-value for trend \\
\hline \multicolumn{5}{|l|}{ CIN2+ prevalence } \\
\hline $\begin{array}{l}\text { Burkina Faso } \\
\text { ( } \mathrm{N}=511 \text { evaluated women) }\end{array}$ & $7 / 54(13 \%)$ & $4 / 102(4 \%)$ & $19 / 355(5 \%)$ & $P=0.09$ \\
\hline $\begin{array}{l}\text { South Africa } \\
\text { ( } N=438 \text { evaluated women) }\end{array}$ & $21 / 44(48 \%)$ & $35 / 101(35 \%)$ & $69 / 293(24 \%)$ & $P<0.001$ \\
\hline \multicolumn{5}{|c|}{ Sensitivity to detect CIN2+ (N $=155)$} \\
\hline HR-HPV & $100 \%$ & $94 \%$ & $85 \%$ & $P=0.07$ \\
\hline Cytology (LSIL) & $92 \%$ & $94 \%$ & $94 \%$ & $P=0.81$ \\
\hline Cytology (HSIL) & $80 \%$ & $72 \%$ & $57 \%$ & $P=0.03$ \\
\hline VIA/VILI & $68 \%$ & $64 \%$ & $58 \%$ & $P=0.32$ \\
\hline HPV + Cytology & $100 \%$ & $100 \%$ & $98 \%$ & $P=1.00$ \\
\hline HPV + VIA/VILI & $100 \%$ & $100 \%$ & $93 \%$ & $P=1.00$ \\
\hline Cytology + VIA/VILI & $96 \%$ & $97 \%$ & $96 \%$ & $P=0.99$ \\
\hline \multicolumn{5}{|c|}{ Specificity to detect CIN2+ $(N=155)$} \\
\hline HR-HPV & $36 \%$ & $47 \%$ & $63 \%$ & $\mathrm{P}<0.001$ \\
\hline Cytology (LSIL) & $49 \%$ & $50 \%$ & $56 \%$ & $P=0.13$ \\
\hline Cytology (HSIL) & $87 \%$ & $90 \%$ & $91 \%$ & $P=0.30$ \\
\hline VIA/VILI & $77 \%$ & $74 \%$ & $74 \%$ & $P=0.72$ \\
\hline HPV + Cytology (HSIL) & $29 \%$ & $32 \%$ & $41 \%$ & $P=0.02$ \\
\hline HPV + VIAVILI & $30 \%$ & $38 \%$ & $49 \%$ & $P=0.002$ \\
\hline Cytology (HSIL) + VIA/VILI & $42 \%$ & $42 \%$ & $47 \%$ & $P=0.28$ \\
\hline
\end{tabular}

